\title{
Elevated Neutrophil-to-Lymphocyte Ratio May Be Associated with Overactive Bladder Patients
}

D Mehmet Gökhan Çulha, (D) Recep Burak Değirmentepe, (D) Sait Özbir, (D) Samir Agalarov, (D) Muammer Bozkurt, (D) Erkan Merder, (D) Fatih Altunrende, (D) Alper Ötünçtemur

University of Health Sciences Turkey, Prof. Dr. Cemil Taş̧̧ıoğlu City Hospital, Clinic of Urology, İstanbul, Turkey

\section{Abstract}

Objective: Overactive bladder $(\mathrm{OAB})$ may be interrelated with chronic inflammation. The aim of this study was to assess the role of neutrophillymphocyte ratio (NLR) levels in men and women with OAB symptoms.

Methods: Between January 2017 and February 2018, a total of 157 subjects (77 OAB patients and 80 controls) were included in the study. The subjects divided into two groups. Group 1=OAB patients and group $2=$ normal controls. Patients with active urinary tract infections, previous pelvic surgery or neurogenic patients were excluded. The enrolled both patients and control group were questioned using the 8-item OAB questionnaire (OAB-v8) complete blood count and serum C-reactive protein (CRP) levels were measured in the first visit.

Results: The mean NLR was $1.73 \pm 0.67$ in patients and $1.48 \pm 0.75$ in control groups $(p<0.001)$. The NLR and CRP levels were both statistically significant higher in OAB patient group ( $p=0.03$ for CRP and $p=0.001$ for NLR). There was positive correlation between OAB-v8 scores and NLR $(\mathrm{p}<0.001, \mathrm{r}=0.215)$

Conclusion: High serum NLR levels were observed in OAB patients. Our results support the association between chronic inflammations of the bladder in OAB patients.

Keywords: Overactive bladder, neutrophil-to-lymphocyte ratio, urgency, inflammation

\section{INTRODUCTION}

Overactive bladder (OAB) is a multifactorial and widespread health disorder, identified by the International Continence Society as an Urgent Characterizing syndrome, with or without urinary incontinence, often accompanied by frequency and nocturia when there is no urinary tract infection or any other kind of apparent pathology (1). OAB is a common situation in both sexes and has a noteworthy effect on quality of life and economic burden (2-4). OAB is a highly extensive condition affecting $12-17 \%$ of men and women. Approximately $28 \%$ of men and $49 \%$ of women reporting symptoms of OAB women report urinary incontinence (UI) with urgent UI (4).
Epidemiological studies have suggested that inflammation may play a role in the growth and progress of lower urinary tract symptoms (LUTS). Rohrmann et al. (5) found that men with detectable C-reactive protein (CRP) levels had a higher likelihood of LUTS than men with undetectable CRP levels. Clinical investigations of bladder biopsy findings in patients with $O A B$ show that inflammation is associated with OAB pathophysiology (6). A recent study also demonstrated that higher levels of urinary inflammatory biomarkers are identified in patients with $\mathrm{OAB}(7)$. While the molecular mechanisms underlying the etiology and pathophysiology of $\mathrm{OAB}$ are still largely unknown, the interaction between the urinary system and the immune system has been shown to have a notable part in the pathophysiology of $\mathrm{OAB}$

Address for Correspondence: Mehmet Gökhan Çulha, University of Health Sciences Turkey, Prof. Dr. Cemil Tașçıoğlu

Received: 17.07 .2019

City Hospital, Clinic of Urology, İstanbul, Turkey

Phone: +90 5325620496 E-mail: gokhan_culha64@hotmail.com ORCID ID: orcid.org/0000-0003-1687-5349

Cite this article as: Çulha MG, Değirmentepe RB, Özbir S, Agalarov S, Bozkurt M, Merder E, Altunrende F,

Ötünçtemur A. Elevated Neutrophil-to-Lymphocyte Ratio May Be Associated with Overactive Bladder Patients.

Eur Arch Med Res 2020; 36 (2):125-9

๑Copyright 2020 by the University of Health Sciences Turkey, Prof. Dr. Cemil Taşçığlu City Hospital

European Archives of Medical Research published by Galenos Publishing House. 
(8). Detrusor overactivity has often been regarded as the primary cause of OAB. However, the potential role of inflammatory processes in the pathophysiology of $\mathrm{OAB}$ and development of OAB has not been well assessed. While the monitoring of cytokines in blood plasma may improve our understanding of the process that leads to $O A B$ the technical difficulties and costs related with the use of these inflammatory markers such as interleukins, tumor necrosis factor-alpha, interferon gamma, and CRP, in routine clinical practice may limit their use.

Alternatively, the neutrophil-lymphocyte ratio (NLR) can be rapidly and inexpensively attained from a differential white blood cell (WBC) count. It is a marker of inflammation and predicts the prognosis of disease. The NLR has already been shown to play a role in inflammatory diseases (9-11), but its relationship with $O A B$ continues to be vague. Thus, the aim of the study we conducted was to evaluate the association between $\mathrm{OAB}$ and inflammation, as measured by the NLR, among men and women with $\mathrm{OAB}$.

\section{METHODS}

Cross-sectional data was collected female patients with $\mathrm{OAB}$ based on the symptoms of urgency with/without urgency incontinence who visited outpatient urological clinics for treatment from January 2017 to February 2018. The study was confirmed by the Institutional Review Board of Okmeydanı Training and Research Hospital (2017/380) and written consent was acquired from all participants. The study was carried out in accordance with the principles of the Helsinki Declaration. Power analysis to estimate the sample size was based on the CRP values in a similar previous study (12). Assuming a power of 0.80 and $\alpha$ value of 0.05 , a sample size of 75 patients was found to be sufficient for each group.

Baseline characteristics were collected from each patient's medical records and included data on age, body mass index (BMI), smoking, previous diseases, history of bladder or urethral surgery, medication, and comorbidities. All patients had urinary ultrasonography and urine examination; urine culture, serum creatinine, and complete blood count were examined for the differential diagnosis. Patients with previous bladder or urethral surgery, active urinary tract infections, medication use for $\mathrm{OAB}$, diabetes or possible neurogenic lesions, cardiovascular diseases, malignancy were excluded from the study. The control group included individuals with no active urologic disease or LUTS. Uroflowmetry and postvoid residual urine volume were measured at the first visit to rule out bladder outlet obstruction. The enrolled both patients and control group were also questioned using the 8-item OAB questionnaire (OAB-v8) (13). Also, a 3-day voiding diary was kept, which was used to verify urgency, urgency urinary incontinence, and functional bladder capacity.

The complete blood count was obtained by a hematology analyzer (Coulter Gen-S Hematology Analyzer; Beckman Coulter Corp, Hialeah, FL, USA).The total WBC was recorded, along with the neutrophil and lymphocyte counts. The NLR was calculated by dividing the neutrophil count by the lymphocyte count and platelet count by the lymphocyte count, respectively.

\section{Statistical Analysis}

SPSS 22.0 program (SPSS, Chicago, IL, USA) was used in the analyzes. The distribution of variables was determined by means of using the Kolmogorov-Smirnov test. Independent samples t-test and Mann-Whitney $U$ test were used for the analysis of quantitative independent data. Pearson chi-square test was used in the analysis of qualitative data. Pearson correlation analysis was used in the correlation analysis. The NLR cut-off value was determined according to the level of specificity and sensitivity obtained from the area under the receiver operator characteristics (ROC) curve for patients with and without OAB. A $p$ value of $<0.05$ was considered to be statistically significant.

\section{RESULTS}

A total of 77 patients and 80 control subjects were inscribed. The demographic data are listed in Table 1. Age, BMI, smoking and alcohol consumption status were not significantly different between the groups $(p>0.05)$.

The mean NLR was $1.73 \pm 0.67$ in patients and $1.48 \pm 0.75$ in control groups $(p=0.001)$. The mean neutrophil, lymphocyte, platelet, NLR and CRP levels were given in Table 2. The NLR and CRP levels were both statistically significant higher in OAB patient group ( $p=0.03$ for CRP and $p=0.001$ for NLR). There was positive correlation between OAB v8 scores and NLR $(p<0.001$, $r=0.215$ ) (Figure 1).

\begin{tabular}{|l|l|l|l|}
\hline \multicolumn{4}{|l|}{ Table 1. Demographic data of the subjects } \\
\hline & $\begin{array}{l}\text { OAB Patients } \\
(\mathbf{n}=77)\end{array}$ & $\begin{array}{l}\text { Control } \\
(\mathbf{n}=\mathbf{8 0})\end{array}$ & $\mathbf{p}$ \\
\hline Age (mean, SD) & $45.15 \pm 16.54$ & $43.31 \pm 15.39$ & $0.47 \mathrm{t}$ \\
\hline BMI (mean, SD) & $27.05 \pm 5.17$ & $27.45 \pm 4.38$ & $0.59^{\mathrm{t}}$ \\
\hline Smoking status (n/\%) & $15 / 19.4$ & $14 / 17.5$ & $0.193 \mathrm{c}$ \\
\hline $\begin{array}{l}\text { OAB v8 score } \\
\text { (mean, SD) }\end{array}$ & $18.57 \pm 2.84$ & $0.35 \pm 1.01$ & $<0.001 \mathrm{u}$ \\
\hline
\end{tabular}

tIndependent t-test, 'Chi-square test, uMann-Whitney $\mathrm{U}$ test, SD: Standard deviation, OAB v8: 8-item overactive bladder questionnaire 
The ROC area of serum NLR levels to predict OAB was 0.66 $(p=0.013,95 \%$ confidence interval $0.57-0.75)$. The NLR cut-off point of 1.39 (sensitivity $65.4 \%$, specificity $61 \%$, positive predictive value 59.1\%, negative predictive value 62.4\%) (Figure 2).

\section{DISCUSSION}

This is the first study to investigate the relationship between $O A B$ and inflammatory markers NLR. Results of this crosssectional study demonstrate a significant relationship between the elevated NLR and OAB symptoms in patients. These results assist to hypothesis that inflammation is effective in the development of OAB. The findings from our study show that

\begin{tabular}{|l|l|l|l|}
\hline \multicolumn{4}{|l|}{ Table 2. Comparison of OAB patient and control groups } \\
\hline & $\begin{array}{l}\text { OAB Patients } \\
(\mathbf{n}=77)\end{array}$ & Control $(\mathbf{n}=\mathbf{8 0})$ & $\mathbf{p}$ \\
\hline $\begin{array}{l}\text { Hemoglobin }(\mathrm{g} / \mathrm{dL}) \\
{[\text { Med }(\mathrm{Q} 1-\mathrm{Q})]}\end{array}$ & $14.70(13-15)$ & $13.35(12.60-14)$ & $0.151^{\mathrm{u}}$ \\
\hline $\begin{array}{l}\text { Neutrophil }(103 / \mu \mathrm{L}) \\
{[\text { Med }(\mathrm{Q} 1-\mathrm{Q} 3)]}\end{array}$ & $3.89(2.7-4.5)$ & $3.5(2.6-4.3)$ & $0.03^{\mathrm{u}}$ \\
\hline Lymphocyte $\left(10^{3} / \mu \mathrm{L}\right)$ & $2.58 \pm 0.71$ & $2.51 \pm 0.63$ & $0.458^{\mathrm{t}}$ \\
\hline Monocyte $\left(10^{3} / \mu \mathrm{L}\right)$ & $0.54 \pm 0.19$ & $0.59 \pm 0.12$ & $0.064^{\mathrm{t}}$ \\
\hline Basophil $\left(10^{3} / \mu \mathrm{L}\right)$ & $0.18 \pm 0.12$ & $0.25 \pm 0.16$ & $0.188^{\mathrm{t}}$ \\
\hline Eosinophil $\left(10^{3} / \mu \mathrm{L}\right)$ & $0.03 \pm 0.03$ & $0.03 \pm 0.02$ & $0.381^{\mathrm{t}}$ \\
\hline Platelet $\left(10^{3} / \mu \mathrm{L}\right)$ & $100.82 \pm 38.04$ & $101.89 \pm 45.06$ & $0.402^{\mathrm{t}}$ \\
\hline CRP $(\mathrm{mg} / \mathrm{L})$ & $4.87 \pm 5.86$ & $3.03 \pm 1.96$ & $0.372^{\mathrm{t}}$ \\
\hline NLR & $1.73 \pm 0.67$ & $1.48 \pm 0.75$ & $0.001^{\mathrm{t}}$ \\
\hline $\begin{array}{l}\text { OAB: Overactive bladder, NLR: Neutrophil-to-lymphocyte ratio, } \\
\text { t-test, undependent }\end{array}$ \\
\hline
\end{tabular}

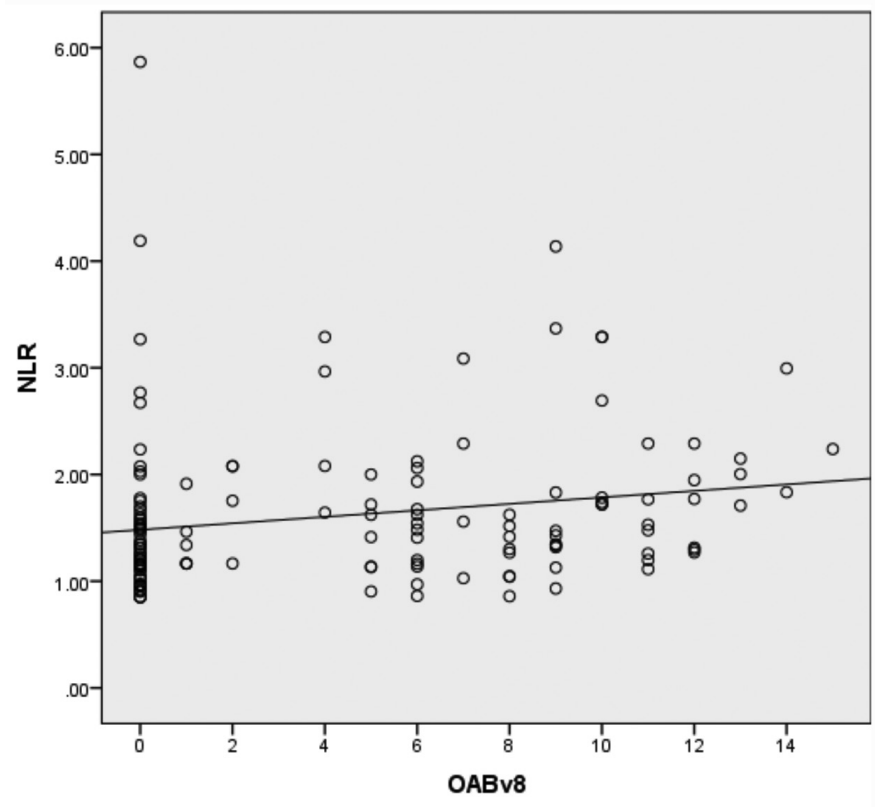

Figure 1. The Association of Serum NLR with OAB scores OAB: Overactive bladder, NLR: Neutrophil-to-lymphocyte ratio this inflammatory marker is suitable for screening to identify patients with $O A B$.

Prior studies have shown that systemic inflammatory processes are allied with $\mathrm{OAB}$. It has shown that $\mathrm{OAB}$ may result from sterile trauma or stress, or both, and is based on evidence of bladder excessive urinary inflammation cytokines and chemokines, and is related to bladder inflammation involving an interaction involving bladder overactive parasympathetic and peptidergic/ sensory disturbances (7). A bladder biopsy study in patients with $O A B$ also suggests that bladder inflammation is associated with OAB pathophysiology (6). Another study revealed that intravesical instillation of cyclooxygenase-2 inhibitor reduced detrusor hyperactivity and decreased the expression of inflammatory modulators in rat model (14). Additionally, Kupelian at al. (15) showed increased risk of OAB with higher CRP levels, which is an inflammatory marker, in both men and women in their study. Baseline data from the Reduction by Dutasteride of Prostate Cancer Events trial demonstrate a relatively weak but significant correlation between the degree of inflammation and LUTS assessed by the International Prostate Symptom score (IPSS). Chronic inflammation was related with both storage and voiding sub scores of the IPSS (16). Studies have suggested that the alikeness of clinical trials with advanced inflammatory markers in male and female genders might show a familiar pathophysiology responsible for $\mathrm{OAB}$.

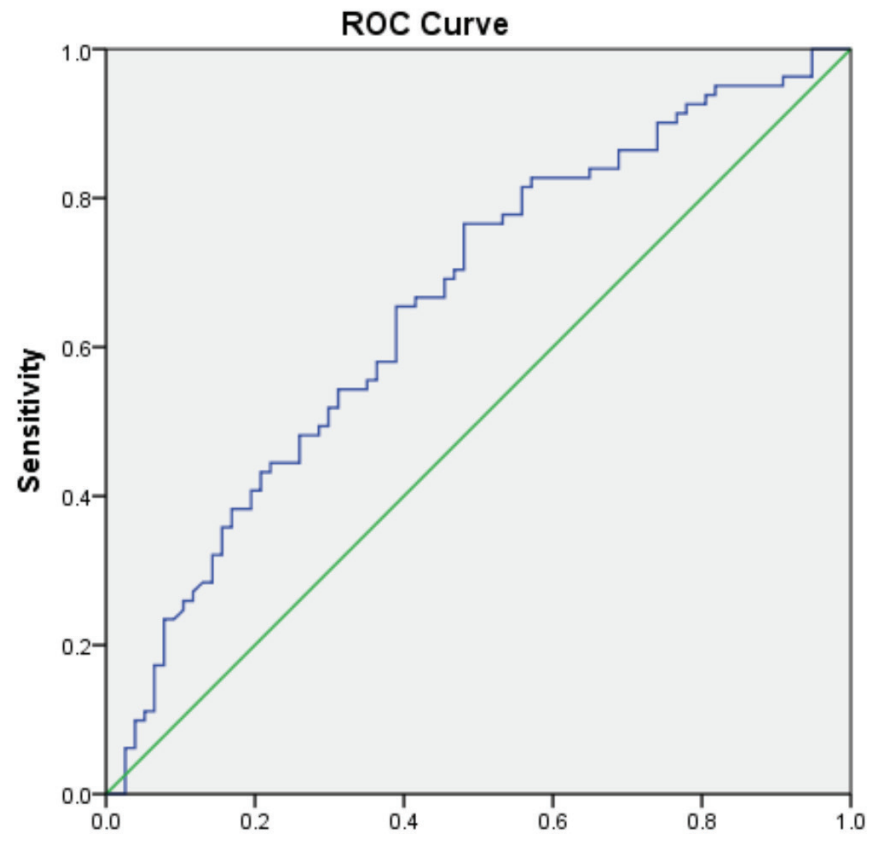

Figure 2. The ROC curve of NLR. Cut-off point 1.39 [area under curve: 0.66 (0.57-0.75)] was considered significant for OAB

ROC: Receiver operator characteristics, NLR: Neutrophil-lymphocyte ratio, OAB: Overactive bladder 
While these inflammatory markers may improve our understanding of $\mathrm{OAB}$, the technical difficulties and costs associated with measuring them in routine clinical practice limit their use. Therefore, the goal of this study is to determine the relationships between OAB and NLR quickly and cheaply.

Neutrophils have several potent effector mechanisms to combat and eventually devastate tissues. Oxidative mechanisms that result in the production of reactive oxygen species, the release of several peptides, and the formation of neutrophil extracellular traps have detrimental effects on bladder (17). Since neutrophilia and lymphocytopenia occur after systemic inflammation (18), the increase in NLR found in those with chronic inflammation may also affect the patients with $\mathrm{OAB}$.

Recently, studies have shown that chronic inflammation is associated with an increased neutrophil lymphocyte ratio. The NLR have been used to detect inflammation in cardiovascular diseases, prevalent chronic diseases, infectious diseases, various kinds of malignancies, and several other inflammatory diseases (19-22). However, NLR has not previously been used to determine the association between inflammation and $O A B$. In this study, we found significant differences in the associations of $O A B$ and the NLR between the patients with OAB and control group.

Systemic inflammation may, therefore, be one cause of OAB through unknown mechanisms. This study demonstrated that severity of disease was affected by the inflammatory markers that we studied. There were, however, limitations to our study that are worth mentioning. These include the nature of crosssectional, as well as having a relatively small sample size. Additionally, the lack of subsequent NLR levels after treatment limits its potential role as a follow-up biomarker. Further research on the associations of OAB with the NLR is required to verify the results of our study.

\section{CONCLUSION}

This study shows that the serum NLRs of the OAB patients is higher than normal controls. These consequences extra proof to the accrued proof backing up an inflammatory role in the growth and progress of OAB. Longer studies are needed to better define the effect of inflammation and to inform the development of the interventions of anti-inflammatory agents in $\mathrm{OAB}$ treatment.

\section{Ethics}

Ethics Committee Approval: The study was confirmed by the Institutional Review Board of Okmeydanı Training and Research Hospital (2017/380).
Informed Consent: Written consent was acquired from all participants.

Peer-review: Externally and internally peer-reviewed.

\section{Authorship Contributions}

Concept: M.G.Ç., R.B.D., Design: M.G.Ç., S.Ö., Data Collection or Processing: R.B.D., M.B., S.A., Analysis or Interpretation: M.G.C., A.Ö., Literature Search: R.B.D., M.G.Ç., F.A., E.M., Writing: M.G.Ç.

Conflict of Interest: No conflict of interest was declared by the authors.

Financial Disclosure: The authors declared that this study received no financial support.

\section{REFERENCES}

1. Abrams P, Artibani W, Cardozo L, Dmochowski R, van Kerrebroeck P, Sand P, et al. Reviewing the ICS 2002 terminology report: the ongoing debate. Neurourol Urodyn 2009;28:287.

2. Milsom I, Abrams P, Cardozo L, Roberts RG, Thüroff J, Wein AJ. How widespread are the symptoms of an overactive bladder and how are they managed? A population-based prevalence study. BJU Int 2001;87:760-6.

3. Stewart WF, Van Rooyen JB, Cundiff GW, Abrams P, Herzog AR, Corey R, et al. Prevalence and burden of overactive bladder in the United States. World J Urol 2003;20:327-36.

4. Irwin DE, Milsom I, Hunskaar S, Reilly K, Kopp Z, Herschorn S, et al. Population-based survey of urinary incontinence, overactive bladder, and other lower urinary tract symptoms in five countries: results of the EPIC study. Eur Urol 2006;50:1306-14.

5. Rohrmann S, De Marzo AM, Smit E, Giovannucci E, Platz EA. Serum C-reactive protein concentration and lower urinary tract symptoms in older men in the Third National Health and Nutrition Examination Survey (NHANES III). Prostate 2005;62:27-33.

6. Comperat E, Reitz A, Delcourt A, Capron F, Denys P, Chartier-Kastler E. Histologic features in the urinary bladder wall affected from neurogenic overactivity--a comparison of inflammation, oedema and fibrosis with and without injection of botulinum toxin type A. Eur Urol 2006;50:105864.

7. Tyagi P, Barclay D, Zamora R, Yoshimura N, Peters K, Vodovotz Y, et al. Urine cytokines suggest an inflammatory response in the overactive bladder: a pilot study. Int Urol Nephrol 2010;42:629-35.

8. Chung SD, Liu HT, Lin H, Kuo HC. Elevation of serum c-reactive protein in patients with $\mathrm{OAB}$ and IC/BPS implies chronic inflammation in the urinary bladder. Neurourol Urodyn 2011;30:417-20.

9. Imtiaz F, Shafique K, Mirza SS, Ayoob Z, Vart P, Rao S. Neutrophil lymphocyte ratio as a measure of systemic inflammation in prevalent chronic diseases in Asian population. Int Arch Med 2012;5:2.

10. Duksal F, Alaygut D, Güven AS, Ekici M, Oflaz MB, Tuncer R, et al. Neutrophil-lymphocyte ratio in children with familial Mediterranean fever: Original article. Eur J Rheumatol 2015;2:20-3.

11. Celikbilek M, Dogan S, Ozbakır O, Zararsız G, Kücük H, Gürsoy S, et al. Neutrophil-lymphocyte ratio as a predictor of disease severity in ulcerative colitis. J Clin Lab Anal 2013;27:72-6. 
12. Tarhan H, Ekin RG, Can E, Cakmak O, Yavascan O, Mutlubas Ozsan F, et al. C-reactive protein levels in girls with lower urinary tract symptoms. J Pediatr Urol. 2016;12:105.

13. Acquadro C, Kopp Z, Coyne KS, Corcos J, Tubaro A, Choo MS, et al. Translating overactive bladder questionnaires in 14 languages. Urology 2006;67:536-40.

14. Jang J, Park EY, Seo SI, Hwang TK, Kim JC. Effects of intravesical instillation of cyclooxygenase-2 inhibitor on the expression of inducible nitric oxide synthase and nerve growth factor in cyclophosphamideinduced overactive bladder. BJU Int 2006;98:435-9.

15. Kupelian V, Rosen RC, Roehrborn CG, Tyagi P, Chancellor MB, McKinlay JB. Association of overactive bladder and C-reactive protein levels. Results from the Boston Area Community Health (BACH) Survey. BJU Int 2012;110:401-7.

16. Nickel JC, Roehrborn CG, O'Leary MP, Bostwick DG, Somerville MC, Rittmaster RS. The relationship between prostate inflammation and lower urinary tract symptoms: examination of baseline data from the REDUCE trial. Eur Urol 2008;54:1379-84.

17. Hermosilla C, Caro TM, Silva LM, Ruiz A, Taubert A. The intriguing host innate immune response: novel anti-parasitic defence by neutrophil extracellular traps. Parasitology 2014;141:1489-98.
18. Zahorec R. Ratio of neutrophil to lymphocyte counts--rapid and simple parameter of systemic inflammation and stress in critically ill. Bratisl Lek Listy 2001;102:5-14.

19. Kurtul BE, Ozer PA. The Relationship between Neutrophil-to-lymphocyte Ratio and Age-related Macular Degeneration. Korean J Ohthalmol 2016;30:377-81.

20. Yoon NB, Son C, Um SJ. Role of the neutrophil-lymphocyte count ratio in the differential diagnosis between pulmonary tuberculosis and bacterial community-acquired pneumonia. Ann Lab Med 2013;33:10510.

21. Liu CL, Lee JJ, Liu TP, Chang YC, Hsu YC, Cheng SP. Blood neutrophilto-lymphocyte ratio correlates with tumor size in patients with differentiated thyroid cancer. J Surg Oncol 2013;107:493-7.

22. Kaya H, Ertaş F, İslamoğlu Y, Kaya Z, Atılgan ZA, Çil H, et al. Association between neutrophil to lymphocyte ratio and severity of coronary artery disease. Clin Appl Thromb Hemost 2014;20:50-4. 